\title{
Percepção da acessibilidade dos metroviários com deficiência
}

\author{
Ana Paula Veras de Oliveira Amaral \\ Engenheira de Segurança do Trabalho. Mestranda do Programa de Pós-Graduação em Promoção da Saúde, \\ Desenvolvimento Humano e Sociedade da Universidade Luterana do Brasil - Ulbra \\ 凹anaveras@gmail.com \\ Ana Maria Pujol Vieira dos Santos \\ Bióloga - Docente do Mestrado em Promoção da Saúde, Desenvolvimento Humano e Sociedade/Ulbra \\ Nádia Teresinha Schröder \\ Bióloga - Docente do Mestrado em Promoção da Saúde, Desenvolvimento Humano e Sociedade/Ulbra
}

\begin{abstract}
Resumo:
A inclusão social das pessoas com deficiência no mercado de trabalho tem sido amplamente discutida e incentivada, contudo para muitos trabalhadores, encontrar e manter um emprego, ainda é um desafio. Este estudo teve por objetivo identificar a percepção dos trabalhadores com deficiência do Metrô-DF quanto à acessibilidade no seu ambiente de trabalho. 0 método utilizado foi uma pesquisa de campo com abordagem quantitativa, utilizando um questionário com seis dimensões da acessibilidade e escala de concordância Likert. Os dados receberam tratamento estatístico, sendo que os resultados das variáveis nominais foram expressos através de análises de frequência e os resultados das variáveis contínuas e ordinais através de média \pm desvio padrão. No total, 40 trabalhadores aceitaram participar da pesquisa, 24 com deficiência física, nove auditiva e sete visual. As médias das percepções mais elevadas foram encontradas nas dimensões comunicacional, atitudinal, instrumental e arquitetônica, com valores estabelecidos como concordância parcial, seguida pela metodológica e programática, apresentando valores de neutralidade. Obtiveram-se indicadores relativos às dimensões da acessibilidade onde cada tipo de deficiência especificou as possibilidades de melhoria para uma inclusão adequada por parte da empresa. Os resultados identificaram as características dos trabalhadores com deficiência e evidenciaram os principais aspectos a serem aprimorados pela empresa relacionados com as seis dimensões da acessibilidade. Destacou-se a necessidade dos trabalhadores tornarem-se colaboradores ativos para a construção da igualdade de condições no ambiente de trabalho.
\end{abstract}

Palavras-chave: Trabalho, Pessoa com deficiência, Acessibilidade, Inclusão social.

\section{Perception of accessibility for disabled subway workers}

\begin{abstract}
:
The social inclusion of people with disabilities in the labor market has been widely discussed and encouraged, however for many workers, finding and maintaining a job is still a challenge. This study aimed to identify the perception of workers with disabilities in Metrô-DF regarding accessibility in their work environment. The method used was a field research with a quantitative approach, using a questionnaire with six dimensions of accessibility and Likert agreement scale. The data received statistical treatment, and the results of the nominal variables were expressed through frequency analysis and the results of continuous and ordinal variables through mean \pm standard deviation. In total, 40 workers agreed to participate in the research, 24 with physical disabilities, nine with hearing
\end{abstract}


impairments and seven with visual impairments. The means of the highest perceptions were found in the communicational, attitudinal, instrumental and architectural dimensions, with values established as partial agreement, followed by methodological and programmatic, showing values of neutrality. Indicators were obtained regarding the dimensions of accessibility where each type of disability specified the possibilities for improvement for an adequate inclusion by the company. The results identified the characteristics of workers with disabilities and highlighted the main aspects to be improved by the company related to the six dimensions of accessibility. It was highlighted the need for workers to become active collaborators for the construction of equal conditions in the work environment.

Keywords: Work, Disabled person, Accessibility, Social inclusion.

\section{Percepción de accesibilidad de los trabajadores del metro discapacitados}

\section{Resumen:}

La inclusión social de las personas con discapacidad en el mercado laboral ha sido ampliamente discutida y alentada, sin embargo, para muchos trabajadores, encontrar y mantener un trabajo sigue siendo un desafío. Este estudio tuvo como objetivo identificar la percepción de los trabajadores con discapacidad en Metrô-DF con respecto a la accesibilidad en su entorno de trabajo. El método utilizado fue una investigación de campo con un enfoque cuantitativo, utilizando un cuestionario con seis dimensiones de accesibilidad y escala de acuerdo de Likert. Los datos recibieron tratamiento estadístico, y los resultados de las variables nominales se expresaron a través del análisis de frecuencia y los resultados de las variables continuas y ordinales a través de la media \pm desviación estándar. En total, 40 trabajadores acordaron participar en la investigación, 24 con discapacidades físicas, nueve con impedimentos auditivos y siete con impedimentos visuales. Los medios de las percepciones más altas se encontraron en las dimensiones comunicativas, actitudinales, instrumentales y arquitectónicas, con valores establecidos como acuerdo parcial, seguidos de metodológicos y programáticos, que muestran valores de neutralidad. Se obtuvieron indicadores sobre las dimensiones de accesibilidad donde cada tipo de discapacidad especificaba las posibilidades de mejora para una adecuada inclusión por parte de la empresa. Los resultados identificaron las características de los trabajadores con discapacidad y destacaron los principales aspectos que la empresa debe mejorar en relación con las seis dimensiones de accesibilidad. Se destacó la necesidad de que los trabajadores se conviertan en colaboradores activos para la construcción de igualdad de condiciones en el entorno laboral.

Palabras clave: Trabajo, Personas con discapacidad, Accesibilidad, Inclusión social.

\section{INTRODUÇÃO}

A segregação das pessoas com deficiência ocorre desde a antiguidade e continua no cotidiano de nossa sociedade. A marginalização revela o destino excludente da grande maioria da população mundial que, inevitavelmente gera desigualdades sociais. Na condição de seres humanos, um fato inegável é que, nenhum indivíduo é igual ao outro e suas singularidades se manifestam de diferentes formas. Essa diversidade deve ser respeitada, não apenas por uma questão de sensatez, mas de direito. E na busca de igualdade nas diferenças, a acessibilidade é um importante instrumento no processo de equidade de oportunidades. A eliminação das barreiras, as quais impedem o pleno exercício da liberdade e dos direitos 
fundamentais por parte das pessoas com deficiência, está relacionada com vários aspectos sociais que abrange a vivência destes indivíduos, nas áreas de educação, trabalho, habitação, cultura e lazer (SILVA; SILVA, 2015).

O Brasil é um país com um grande número de deficientes. No censo de 2010, 45,6 milhões de pessoas declararam ter pelo menos uma das deficiências investigadas. Isso corresponde a $23,9 \%$ da população brasileira, das quais $18,8 \%$ são deficientes visuais, $7,0 \%$ possuem deficiência motora, 5,1\% deficiência auditiva e 1,4\% mental/intelectual (IBGE, 2010). Em relação aos trabalhadores com deficiência, o Ministério do Trabalho (MTb, 2018) divulga a Relação Anual de Informações Sociais (RAIS), apresentando um mapeamento do mercado formal de trabalho no Brasil. Em 2018 foram registrados 487 mil empregos formais para as pessoas com deficiência, sendo contratados $47,3 \%$ deficientes físicos, $18,0 \%$ deficientes auditivos, $15,2 \%$ deficientes visuais, $8,9 \%$ deficientes mental/intelectual e $1,8 \%$ com deficiência múltipla. A inclusão dessa população no ambiente de trabalho tem sido amplamente discutida e incentivada pelos governos federal, estadual, municipal e distrital, através de várias leis, decretos e normas. Entre as ações legais adotadas pelo Estado, destacase a lei de cotas, que é a normatização para empresas públicas ou privadas regidas pela Consolidação das Leis do Trabalho - CLT, com 100 ou mais empregados, para assegurar a oferta de vagas à pessoas com deficiência. As cotas reservadas variam entre $2 \%$ a $5 \%$, de acordo com o número total de trabalhadores da empresa.

A admissão e a permanência de pessoas com deficiência no mercado de trabalho devem ocorrer através de colocação competitiva e em igualdade de oportunidades com as demais pessoas. É vedado qualquer tipo de discriminação ou restrição ao trabalho, por motivo de sua condição, em todos os momentos da sua vida laboral, compreende ainda, as fases de recrutamento, seleção, admissão, ascensão profissional, bem como exigência de aptidão plena. As instituições necessitam cumprir os princípios da acessibilidade, assim, as pessoas jurídicas de direito público, privado ou de qualquer natureza são obrigadas a garantir ambientes de trabalho acessíveis e inclusivos. Disponibilizar aos trabalhadores recursos de tecnologia assistiva e adaptações razoáveis no local de trabalho, conforme as especificidades de cada trabalhador. E garantir o direito à participação e ao acesso a cursos, treinamentos, capacitação, planos de carreira e promoções ofertadas pelo empregador (BRASIL, 2015).

Apesar das legislações sobre inclusão social no mundo do trabalho, para muitas 
pessoas com deficiência, encontrar e manter um emprego ainda é um desafio. 0 estudo com pessoas com deficiência para promover a participação no mundo do trabalho realizado por Silva et al. (2019) cita que a inclusão é mais do que a simples contração de pessoas com deficiência, demanda o enfrentamento das barreiras que mantêm os deficientes em situação de desigualdade. Os autores evidenciam o baixo comprometimento das empresas no processo de inclusão no trabalho, juntamente com a falta de políticas intersetoriais efetivas de apoio, cabendo ao indivíduo e seus familiares o empenho para uma inclusão laboral com êxito. As barreiras presentes nas organizações foram investigadas por Oyintonyo et al. (2018) o estudo demonstrou que a maioria dos trabalhadores com deficiência são estigmatizadas como incapazes e menos produtivas. Estas pessoas enfrentam dificuldades em relação ao preconceito e um ambiente de trabalho inóspito, ou seja, um local que não é preparado para atender as particularidades funcionais dos deficientes. Acompanhado pelos baixos salários e a pouca oportunidade de promoção para um novo cargo. Muitos empregadores sustentam equivocadas compreensões sobre as habilidades relacionadas ao trabalho de pessoas com deficiência (BONACCIO et al., 2020). Essas visões negativas, geralmente são resultados de preocupações que permeiam todo o ciclo de trabalho. Os empregadores podem manifestar ainda, discriminação e estereótipos contra pessoas com certos tipos de deficiência. Em particular, deficiências mentais/intelectuais que exigem maior supervisão e atenção (KUZNETSOVA; BENTO, 2018).

As adaptações no local de trabalho não representam uma condição de privilégio ou regalia para estas pessoas. A adequação no ambiente laboral está relacionada com um gerenciamento eficaz e com práticas inclusivas, que podem resultar em infraestruturas apropriadas (PRINCE, 2017). As acomodações no local de trabalho desempenham um aspecto significativo no emprego de pessoas com deficiência e está positivamente correlacionado com a permanência no trabalho (ANAND; SEVAK, 2017). De acordo com Lorenzo e Silva (2017), o desenvolvimento de ações interdisciplinares devido à complexidade de se promover um ambiente inclusivo se faz necessário, uma vez que é fundamental considerar as diferentes necessidades individuais e coletivas de cada grupo de deficiência e ainda atender as demandas do mercado de trabalho. Assim, Gustafsson et al. (2018) define que o processo de inclusão social é favorecido quando, ao desenvolver as tarefas de trabalho, o trabalhador dispõe de oportunidades de usar e ampliar suas competências. No estudo de Messias (2018) foi demonstrada a importância do trabalho para a vida das pessoas com deficiência com a 
apresentação de diversos fatores positivos. Além do amparo financeiro, o trabalho contribuiu com a formação da identidade do trabalhador deficiente, promoção da autoestima, autonomia e pertencimento.

O crescente debate nas sociedades contemporâneas sobre a acessibilidade e inclusão de pessoas com deficiência justifica o tema da pesquisa, que tem recebido cada vez maior importância social. A acessibilidade costuma ser relacionada apenas a questões físicas e arquitetônicas, no entanto apresenta múltiplas dimensões, abrangendo aquelas de natureza comunicacional, informacional, tecnológica, atitudinal e pedagógica. Dessa forma, as ações de promoção à acessibilidade requerem a identificação e eliminação dos diferentes tipos de barreiras, proporcionando a todos os cidadãos desempenharem suas funções na sociedade em igualdade de condições com as demais pessoas (CIANTELLI e LEITE, 2016).

Nesta perspectiva, devido às inúmeras barreiras que dificultam o acesso e a permanência dessas pessoas no mercado de trabalho e considerando a importância desta problemática, o estudo teve como objetivo avaliar as condições de acessibilidade no metrô de Brasília, através da percepção dos trabalhadores com deficiência relacionada às diferentes dimensões da acessibilidade no desenvolvimento das suas atividades laborais. A partir dos dados coletados, espera-se aprimorar ou possibilitar procedimentos inclusivos para que estes possam exercer suas atividades, de acordo com os princípios do conceito da acessibilidade: mobilidade, conforto, segurança e autonomia.

\section{METODOLOGIA}

Trata-se de um estudo descritivo com abordagem quantitativa aplicado na Companhia do Metropolitano do Distrito Federal (Metrô-DF). A companhia é uma empresa pública de direito privado, sob a forma de sociedade por ações e vincula-se à Secretaria de Estado de Transportes do Distrito Federal. No ano de 2019 tinha 1319 trabalhadores, sendo 60 trabalhadores com diferentes tipos de deficiência e lotados em diversos setores do complexo administrativo e operacional da Companhia.

A coleta de dados foi realizada no período de abril a setembro de 2019. A partir da lista dos funcionários com deficiência, obtida junto ao setor de Segurança e Saúde do Trabalho, 
foram localizados os setores de todos os trabalhadores para apresentar a pesquisa individualmente. Em alguns locais foram realizadas até cinco visitas na tentativa de localizar o funcionário, que não estava presente, por motivos de férias, abono de ponto, atestado médico, escalas de plantão ou mudança do local de trabalho devido às demandas pontuais nas demais estações do metrô. Depois do aceite do participante e da assinatura dos Termos de Consentimento Livre Esclarecido - TCLE foi aplicado o questionário. O preenchimento teve duração de aproximadamente 15 minutos, o que não atrapalhou a rotina de trabalho dos deficientes, mesmo aqueles que trabalhavam em ambientes dinâmicos devido ao fluxo de passageiros.

Para a pesquisa foi utilizado o questionário adaptado de Barreto et al. (2012), a fim de descrever a percepção dos participantes sobre a acessibilidade em seus locais de trabalho. 0 instrumento de coleta de dados foi constituído de duas partes, a primeira parte objetivou caracterizar o perfil dos participantes compostos pelas seguintes variáveis demográficas: sexo, idade, escolaridade e faixa de renda. Além disso, foram elencadas categorias de: cargo, tipos de deficiência e utilização de prótese/órtese. A segunda parte compreendeu questões relacionadas às seis dimensões da acessibilidade propostas por Sassaki (2010), que são: acessibilidade arquitetônica, instrumental, comunicacional, metodológica, programática e atitudinal. Ao total o questionário continha 29 perguntas, sendo sete referentes às variáveis demográficas, cinco a acessibilidade arquitetônica, quatro a acessibilidade comunicacional, quatro a acessibilidade metodológica, uma a acessibilidade instrumental, cinco a acessibilidade atitudinal e três a acessibilidade programática.

A percepção dos participantes sobre as dimensões da acessibilidade foi respondida de acordo com a escala Likert de 5 pontos, na qual 1 corresponde a discordo totalmente, 2 a discordo parcialmente, 3 a neutro, 4 a concordo parcialmente e 5 a concordo totalmente. A partir da escala: a média encontrada entre 1 a 1,8 representou discordância total, entre 1,9 a 2,6 discordância parcial, entre 2,7 a 3,4 neutralidade, entre 3,5 a 4,2 concordância parcial e entre 4,3 a 5 representou concordância total (BARRETO et al., 2012).

Os dados receberam tratamento estatístico, sendo que os resultados das variáveis nominais foram expressos através de análises de frequência e os resultados das variáveis contínuas e ordinais através de média e desvio padrão. O teste Qui quadrado foi utilizado para verificar a associação entre as variáveis demográficas com o tipo de deficiência. Para 
comparar a pontuação média entre os tipo de acessibilidade foi utilizado o teste de Kruskal Wallis. O teste de Mann-Whitney foi utilizado para comparar a acessibilidade e o uso de prótese/órtese. Para verificar a normalidade dos dados foi utilizado o teste de Kolmogorov Smirnov. Em todas as análises foi considerado como significativo um $p<0,05$. Para realização das análises foi utilizado o software SPSS 21.0.

O projeto foi submetido e aprovado pelo Comitê de Ética em Pesquisa da Universidade Luterana do Brasil - CEP/ULBRA. E está de acordo com a resolução 466/12 do Conselho Nacional de Ética em Pesquisa (CAAE 09663419.1.0000.5349).

\section{RESULTADOS}

Neste estudo aceitaram participar da pesquisa 40 trabalhadores com deficiência do metrô de Brasília/DF, 24 com deficiência física, nove auditiva e sete visual. Do total de deficientes da empresa sete não quiseram participar do estudo, um solicitou exoneração do cargo, uma estava de licença maternidade, um encontrava-se afastado pelo Instituto Nacional do Seguro Social (INSS) e 10 trabalhadores não foram localizados nos dias da aplicação do questionário.

Foi identificado que a maior ocorrência de deficientes é do sexo masculino (85\%) e idade entre 43 a 59 anos (52,5\%). A deficiência física foi predominante tanto para os homens (61,7\%), como para as mulheres (50\%). Quando analisada a escolaridade a maior frequência está no grupo de ensino superior (42,5\%) e 65\% possuem renda entre 3 a 6 salários mínimos ${ }^{1}$. O único funcionário que relatou possuir renda entre 1 a 3 salários mínimos é portador de deficiência física. Apenas $40 \%$ dos investigados faz uso de algum tipo de prótese, sendo observada uma maior incidência de uso no grupo de deficientes visuais (57,1\%). O cargo mais frequente entre os trabalhadores deficientes é o de Agente de Estação/OTM - Operador de Transporte Metroferroviário (42,5\%), seguido pelo Agente de Segurança Operacional/PSO Profissional de Segurança Operacional (22,5\%), cargos que possuem duas nomenclaturas,

\footnotetext{
${ }^{1}$ salário mínimo de referência $\mathrm{R} \$ 998,00$.
} 
porém realizam as mesmas atividades. Mais da metade dos Agentes de Estação/OTM são deficientes físicos, e 33,3\% dos deficientes auditivos são Agente de Segurança/PSO. Não foi verificada nenhuma associação estatisticamente significativa entre sexo, idade, renda ou uso de prótese com o tipo de deficiência.

Em relação às dimensões de acessibilidade analisadas, as pontuações mais elevadas foram encontradas nas dimensões de acessibilidade comunicacional, atitudinal, instrumental e arquitetônica, com percepção de valores estabelecidos como concordância parcial, seguida pela metodológica e programática, apresentando valores de neutralidade (Tabela 1).

Tabela 1 - Dimensões da acessibilidade percebidas por trabalhadores com deficiência do Metrô-DF no ambiente de trabalho, 2019.

\begin{tabular}{cccccc}
\hline Acessibilidade & $\mathbf{N}$ & Mínimo & Máximo & Média & Desvio padrão \\
\hline Comunicacional & 40 & 1,44 & 5,00 & 3,86 & 1,00 \\
Atitudinal & 40 & 1,00 & 5,00 & 3,80 & 0,91 \\
Instrumental & 40 & 1,00 & 5,00 & 3,65 & 1,29 \\
Arquitetônica & 40 & 1,20 & 5,00 & 3,64 & 1,02 \\
Metodológica & 40 & 1,00 & 5,00 & 3,42 & 0,97 \\
Programática & 40 & 1,00 & 5,00 & 3,09 & 1,10 \\
\hline
\end{tabular}

Resultados expressos através de média \pm desvio padrão

Fonte: Autor, 2019.

Os dados referentes às variáveis de cada dimensão da acessibilidade retratam a percepção mais detalhada dos participantes sobre a acessibilidade em seu ambiente laboral, evidenciando indicadores para uma possível inclusão integral e com qualidade. A acessibilidade comunicacional apresentou o valor mais alto das seis dimensões avaliadas, essa acessibilidade ocorre quando não existe barreira na comunicação, sendo ela interpessoal, em língua de sinais, ou nas formas escritas, incluindo textos em braile. Entretanto, para os deficientes auditivos a média foi de 3,17, valor estabelecido como neutralidade (Tabela 2). Neste grupo, o uso de telefone e fax (item A) apresenta discordância parcial e o uso das tecnologias (item B) e relatórios, manuais e formulários (item C) apresentam valores de neutralidade. Para o grupo de deficientes visuais foram evidenciados também os itens A e B e C com valores definidos na neutralidade. Ressalta-se nesta dimensão que os meios de comunicação da empresa atendem as necessidades dos deficientes físicos. Foi verificada 
diferença significativa de cada indicador da acessibilidade quando comparado o tipo de deficiência.

Tabela 2 - Percepção dos trabalhadores com deficiência do Metrô-DF sobre a acessibilidade Comunicacional no ambiente de trabalho, 2019.

\begin{tabular}{|c|c|c|c|c|c|}
\hline & \multirow{2}{*}{ Acessibilidade Comunicacional } & \multicolumn{3}{|c|}{ Média \pm desvio padrão } & \multirow[b]{2}{*}{$\mathrm{p}$} \\
\hline & & Auditiva & Física & Visual & \\
\hline A & $\begin{array}{l}\text { Os aparelhos telefônicos e o fax são } \\
\text { adaptados de maneira a permitir a } \\
\text { comunicação adequada. }\end{array}$ & $2,33 \pm 1,41$ & $4,04 \pm 1,33$ & $3,14 \pm 1,35$ & $0,02^{* *}$ \\
\hline B & $\begin{array}{l}\text { As tecnologias (computador, laptop, } \\
\text { tablet) utilizadas na empresa } \\
\text { permitem o acesso digital e utilização } \\
\text { de forma adequada. }\end{array}$ & $2,89 \pm 1,45$ & $4,25 \pm 1,40$ & $3,00 \pm 1,63$ & $0,01^{* *}$ \\
\hline C & $\begin{array}{l}\text { Os relatórios, manuais, formulários e } \\
\text { outros materiais de comunicação } \\
\text { escrita são adaptados em linguagem } \\
\text { adequada. }\end{array}$ & $3,33 \pm 1,32$ & $4,38 \pm 0,82$ & $3,43 \pm 1,27$ & $0,01^{* *}$ \\
\hline $\mathrm{D}$ & $\begin{array}{l}\text { Consigo me comunicar de forma } \\
\text { adequada com os demais } \\
\text { trabalhadores. }\end{array}$ & $3,56 \pm 1,13$ & $4,46 \pm 1,20$ & $4,29 \pm 1,11$ & $0,03^{* *}$ \\
\hline \multicolumn{2}{|c|}{ Total } & $3,03 \pm 0,99$ & $4,28 \pm 1,00$ & $3,47 \pm 0,88$ & $0,04^{* *}$ \\
\hline
\end{tabular}

Fonte: Autor, 2019.

Atitudes baseadas em preconceitos e estigmas são barreiras para a inclusão no ambiente de trabalho dos deficientes. De acordo com a Tabela 3 a deficiência visual foi a que apontou maior falha na empresa em promover a sensibilização dos funcionários sobre a inclusão, diversidade e pessoas com deficiência. Mesmo assim, concordaram parcialmente que as pessoas do ambiente de trabalho respeitam, contribuem para a inclusão social, não apresentam atitudes preconceituosas nem discriminatórias e sentem-se à vontade em participar de reuniões comemorativas na empresa. Os deficientes físicos foram os únicos que concordam plenamente que as pessoas do ambiente de trabalho respeitam a diversidade e contribuem para a inclusão social das pessoas com deficiência, enquanto para as outras a concordância foi parcial. 
Tabela 3 - Percepção dos trabalhadores com deficiência do Metrô-DF sobre a acessibilidade Atitudinal no ambiente de trabalho, 2019.

\begin{tabular}{clcccc}
\hline \multicolumn{2}{c}{ Acessibilidade Atitudinal } & \multicolumn{3}{c}{ Média \pm desvio padrão } \\
& Auditiva & Física & Visual & p \\
\hline $\begin{array}{l}\text { A empresa promove a sensibilização } \\
\text { dos funcionários sobre a inclusão, } \\
\text { diversidade e pessoas com } \\
\text { deficiência. }\end{array}$ & $3,11 \pm 1,45$ & $3,29 \pm 1,36$ & $2,43 \pm 1,81$ & 0,52 \\
$\begin{array}{l}\text { Os valores estabelecidos na empresa } \\
\text { favorecem as atitudes de cooperação, } \\
\text { cidadania e respeito dos funcionários. }\end{array}$ & $3,78 \pm 1,30$ & $3,79 \pm 1,32$ & $3,14 \pm 1,45$ & 0,58 \\
& $\begin{array}{l}\text { As pessoas do ambiente de trabalho } \\
\text { respeitam a diversidade e contribuem } \\
\text { para a inclusão social de pessoas com } \\
\text { deficiência. }\end{array}$ & $3,78 \pm 1,09$ & $4,33 \pm 1,09$ & $4,00 \pm 1,16$ & 0,13 \\
$\begin{array}{l}\text { Os demais trabalhadores não } \\
\text { apresentam atitudes preconceituosas } \\
\text { nem discriminatórias no ambiente de } \\
\text { trabalho. }\end{array}$ & $4,11 \pm 1,05$ & $4,17 \pm 1,20$ & $4,00 \pm 1,05$ & 0,69 \\
$\begin{array}{l}\text { Sinto-me à vontade em participar das } \\
\text { reuniões comemorativas na empresa. }\end{array}$ & $4,00 \pm 0,71$ & $3,96 \pm 1,30$ & $3,86 \pm 1,22$ & 0,87 \\
\hline Total & $\mathbf{3 , 7 6 \pm 0 , 9 2}$ & $\mathbf{3 , 9 1} \pm \mathbf{0 , 9 2}$ & $\mathbf{3 , 4 9} \pm \mathbf{0 , 8 9}$ & $\mathbf{0 , 4 6}$ \\
\hline
\end{tabular}

Fonte: Autor, 2019.

Os dados da acessibilidade instrumental representam um ambiente laboral sem barreiras nos instrumentos, utensílios e ferramentas de trabalho e está representada na Tabela 4. Na análise por tipo de deficiência, verificou-se que o deficiente visual avaliou o item como neutro.

Tabela 4 - Percepção dos trabalhadores com deficiência do Metrô-DF sobre a acessibilidade Instrumental no ambiente de trabalho, 2019.

\begin{tabular}{|c|c|c|c|c|c|}
\hline & \multirow{2}{*}{ Acessibilidade Instrumental } & \multicolumn{3}{|c|}{ Média \pm desvio padrão } & \multirow[b]{2}{*}{$\mathbf{p}$} \\
\hline & & Auditiva & Física & Visual & \\
\hline A & $\begin{array}{l}\text { Os equipamentos e instrumentos } \\
\text { que utilizo para a realização das } \\
\text { minhas atividades atendem as } \\
\text { minhas necessidades. }\end{array}$ & $3,56 \pm 1,01$ & $3,83 \pm 1,20$ & $3,14 \pm 1,86$ & 0,58 \\
\hline Total & & $3,56 \pm 1,01$ & $3,83 \pm 1,20$ & $3,14 \pm 1,86$ & 0,58 \\
\hline
\end{tabular}

Fonte: Autor, 2019. 
A acessibilidade arquitetônica está relacionada com a ausência de barreiras em ambientes físicos. Nesta dimensão a média total demonstrou haver poucas barreiras físicas no ambiente de trabalho (Tabela 5). Contudo, observa-se que os deficientes visuais são neutros com relação a esta acessibilidade, destacando o arranjo do ambiente de trabalho, o desenho e instalação dos mobiliários e sinalização de rota acesso. Para os deficientes auditivos obtiveram-se valores igualmente de neutralidade para o acesso e circulação sem barreiras e o nivelamento do piso para a locomoção sem empecilhos ou barreiras.

Tabela 5 - Percepção dos trabalhadores com deficiência do Metrô-DF sobre a acessibilidade Arquitetônica no ambiente de trabalho, 2019.

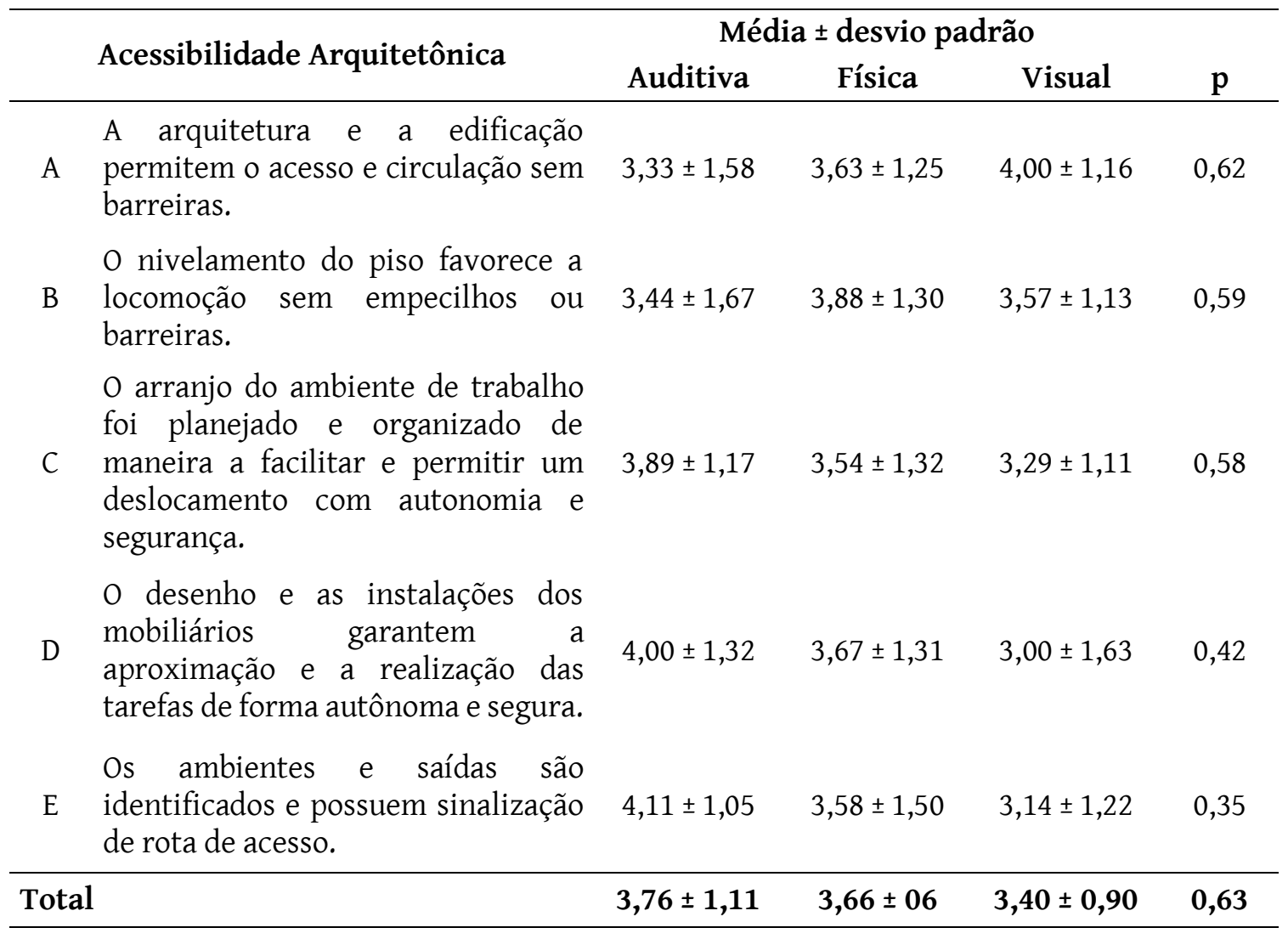

Fonte: Autor, 2019.

A acessibilidade metodológica refere-se a não haver barreiras nos métodos e técnicas de trabalho. Os deficientes físicos concordaram parcialmente com esta dimensão, enquanto os auditivos e visuais foram neutros (Tabela 6). Nesse cenário, os deficientes físicos e visuais foram parciais no item de treinamento adequado e acessível para o melhor desempenho da função, e para os deficientes auditivos este valor foi neutro. Quando responderam se as 
atividades que realizavam foram repensadas e adaptadas para serem executadas por uma pessoa com deficiência, para todos os três tipos de deficiência houve neutralidade. Os deficientes visuais foram neutros para o item de contribuições nas atividades que realizam e para assumir responsabilidades. Os deficientes auditivos e físicos concordaram parcialmente com esses itens.

Tabela 6 - Percepção dos trabalhadores com deficiência do Metrô-DF sobre a acessibilidade Metodológica no ambiente de trabalho, 2019.

\begin{tabular}{|c|c|c|c|c|c|}
\hline & \multirow{2}{*}{ Acessibilidade Metodológica } & \multicolumn{3}{|c|}{ Média \pm desvio padrão } & \multirow[b]{2}{*}{$\mathbf{p}$} \\
\hline & & Auditiva & Física & Visual & \\
\hline A & $\begin{array}{l}\text { Recebi treinamento adequado e } \\
\text { acessível para o melhor } \\
\text { desempenho da minha função. }\end{array}$ & $2,78 \pm 1,32$ & $3,92 \pm 1,10$ & $3,71 \pm 1,25$ & $0,04^{* *}$ \\
\hline B & $\begin{array}{l}\text { As atividades que realizo foram } \\
\text { repensadas e adaptadas para serem } \\
\text { executadas por uma pessoa com } \\
\text { deficiência. }\end{array}$ & $2,78 \pm 1,09$ & $2,88 \pm 1,39$ & $2,57 \pm 1,27$ & 0,87 \\
\hline C & $\begin{array}{l}\text { Sinto-me à vontade em sugerir } \\
\text { contribuições e melhorias para as } \\
\text { atividades que realizo. }\end{array}$ & $4,11 \pm 0,60$ & $4,00 \pm 1,32$ & $2,71 \pm 1,38$ & $0,04^{* *}$ \\
\hline $\mathrm{D}$ & $\begin{array}{l}\text { A instituição proporciona condições } \\
\text { para que eu possa assumir } \\
\text { responsabilidades e tomar decisões. }\end{array}$ & $3,67 \pm 1,12$ & $3,58 \pm 1,32$ & $2,71 \pm 1,38$ & 0,25 \\
\hline Tota & & $3,33 \pm 0,77$ & $3,59 \pm 0,95$ & $2,93 \pm 1,17$ & 0,39 \\
\hline
\end{tabular}

Fonte: Autor, 2019.

A última dimensão avaliada foi à acessibilidade programática, que significa a eliminação de barreiras presentes nos textos normativos (leis, decretos, normas de serviços, manuais operacionais, entre outros). O item C, promoção de novos cargos, os deficientes auditivos e físicos consideraram esse item como neutro e os visuais como discordância parcial. Os deficientes físicos e visuais também se mostraram imparciais em relação aos itens A e B (Tabela 7). 
Tabela 7 - Percepção dos trabalhadores com deficiência do Metrô-DF sobre a acessibilidade Programática nas empresas, 2019.

\begin{tabular}{llcccc}
\hline \multicolumn{2}{l}{ Acessibilidade Programática } & \multicolumn{2}{c}{ Média \pm desvio padrão } \\
& Auditiva & Física & Visual & p \\
\hline $\begin{array}{l}\text { As empresas possuem uma política } \\
\text { de contratação de pessoas com } \\
\text { qualquer deficiência e em qualquer } \\
\text { grau. }\end{array}$ & & & & \\
$\begin{array}{l}\text { As condutas que devem ser } \\
\text { utilizadas na realização das } \\
\text { atividades são formuladas de acordo } \\
\text { com as necessidades de uma pessoa } \\
\text { com deficiência. }\end{array}$ & $3,00 \pm 1,38$ & $2,71 \pm 1,50$ & 0,43 \\
$\begin{array}{l}\text { Os programas e políticas de } \\
\text { desenvolvimento e plano de carreira } \\
\text { dão condições às pessoas com } \\
\text { deficiência de serem promovidas } \\
\text { para novos cargos. }\end{array}$ & $3,29 \pm 1,43$ & $3,29 \pm 1,11$ & 0,22 \\
Total & & & & \\
\hline
\end{tabular}

Fonte: Autor, 2019.

\section{DISCUSSÃO}

Neste estudo observou-se que a maior frequência de trabalhadores deficientes é do sexo masculino, mesmo sendo o ingresso na empresa por meio de concurso público. $O$ acesso das mulheres ao mercado de trabalho ainda é menor em comparação aos homens, corroborando com as informações da Organização Internacional do Trabalho (OIT, 2018). De acordo com o censo demográfico de 2010, a deficiência motora foi a segunda menor participação na força de trabalho do país, ficando atrás apenas da deficiência mental/intelectual (IBGE, 2010). Contudo, esse cenário foi modificado, e em 2018 os deficientes físicos representaram quase metade dos empregos formais para pessoas com deficiência (MTb, 2018), validando a predominância de trabalhadores com deficiência física deste estudo. Menos da metade dos investigados fazem uso de algum tipo de prótese/órtese. Esse dado demonstra que a maioria dos trabalhadores consegue desenvolver suas capacidades laborativas dentro das suas limitações motoras ou sensoriais.

Quando analisada a escolaridade, a maior frequência está no grupo de ensino superior. E apesar dos cargos mais recorrentes, Agente de Estação/OTM e Agente de Segurança operacional/PSO, possuírem como requisito formação acadêmica de nível médio os 
trabalhadores continuaram sua qualificação profissional. Resultado provável das políticas adotadas pelo governo que têm conduzido às instituições de ensino superior a ofertarem educação cada vez mais inclusiva. Situação identificada na pesquisa de Furlan e Ribeiro (2015) sobre o processo de inclusão no ensino superior em uma universidade do sul de Santa Catarina.

Quanto à remuneração verificou-se a prevalência dos participantes que recebem de 3 a 6 salários mínimos, média salarial maior que a maioria das pessoas que declararam ter pelo menos uma das deficiências investigadas no censo demográfico (IBGE, 2010). Em relação ao rendimento mensal de trabalho, foi observado que $29 \%$ recebem de 1 a 2 salários mínimos. Uma diferença de seis pontos percentuais em comparação aos trabalhadores sem deficiência (34\%). Assim a isonomia de salários é um fator relevante para a equiparação salarial dos trabalhadores públicos com deficiência. Entretanto, quando a análise da população foi por tipo de deficiência observou-se que, para a maioria das pessoas com deficiência motora o rendimento mensal é de $1 / 2$ a 1 salário mínimo, apoiando o dado da pesquisa que encontrou a menor faixa salarial na deficiência física.

A construção da acessibilidade não se limita apenas a acessibilidade arquitetônica (barreiras físicas), mas na associação entre as seis dimensões para a eliminação das diferentes barreiras presentes nas estruturas sociais. Situação observada nesta pesquisa com a interrelação entre as diferentes dimensões, onde as práticas discriminatórias e preconceituosas são identificadas não apenas na acessibilidade atitudinal, mas também nas demais dimensões. A comunicação e a arquitetura podem ser meio de exclusão das pessoas com deficiência. Assim como, a acessibilidade comunicacional e atitudinal podem estimular a interação e o convívio entre todos os trabalhadores rompendo estigmas. E todas as dimensões da acessibilidade podem auxiliar na construção da autonomia dos trabalhadores com deficiência.

Destaca-se com maior índice de satisfação a acessibilidade comunicacional, contudo para os deficientes auditivos e visuais aponta-se a necessidade de ajustes no sistema de comunicação escrita, sonora e hipermídias. A comunicação dependerá de um ambiente social onde a interação seja estimulada, e dessa forma um indivíduo com comprometimento possa ter êxito. Esses resultados corroboram com a investigação de Siebra (2015) realizada com pessoas cegas onde foi identificado que as representações mais negativas partem das pessoas 
videntes, que não conhecem como as pessoas com cegueira vivem, suas competências e capacidades. E para que ocorra a inclusão social faz-se necessário que a sociedade modifique suas atitudes discriminatórias para a construção de uma comunicação eficaz.

Foi evidenciada também a importância do convívio para o desenvolvimento da comunicação para os deficientes auditivos. Na pesquisa realizado por Rosa et al. (2017) sobre interações entre estudantes surdos e ouvintes foi verificado que, por não conseguirem estabelecer uma comunicação na Língua Brasileira de Sinais (Libras), os alunos ouvintes excluem os colegas surdos. E por se identificarem com seus pares, que possuem as mesmas dificuldades e falam a mesma língua gestual, os surdos preferem interagir entre si. Essa constatação também é observada na pesquisa realizada por Friedner (2015) em uma empresa da Índia, demonstrando que os trabalhadores surdos se sentem mais confortáveis com outros trabalhadores surdos devido à facilidade na comunicação. Eles se relacionam na busca coletiva de informações e conhecimentos.

Nesta perspectiva, ressalta-se a importância do Metrô-DF em desenvolver ações que possam viabilizar a comunicação e interação dos trabalhadores com deficiência. Pode-se citar algumas, como por exemplo: adequação dos aparelhos telefônicos, computadores, relatórios e manuais, levando-se em consideração as particularidades que atendam às necessidades de cada usuário; a utilização da Libras por meio de intérprete ou a sensibilização dos demais trabalhadores para desenvolverem a língua de sinais, evitando assim um interlocutor na comunicação; adoção de sistema de leitura e escrita em Braille com a adoção de máquina de escrever, impressora ou softwares específicos para transcrição de Braille; uso de Telephone Device for Deaf - TDD (telefone para deficientes auditivos), meios de voz digitalizados como softwares sintetizadores de voz e outros dispositivos multimídia, tais como, programas de aumento de tela de computador e leitor de tela (BRASIL, 2015).

$\mathrm{Na}$ acessibilidade atitudinal, a média total foi positiva. Foi verificado na pesquisa de Felizardo et al. (2016) sobre inclusão de pessoas com deficiência, que a convivência diminuiu o preconceito que os demais trabalhadores possuíam, melhorando o impacto no clima organizacional. Além do aprendizado que o convívio com os deficientes ocasionou para a vida profissional e pessoal dos trabalhadores. Os resultados encontrados neste estudo corroboram com os dados de Felizardo et al. (2016), pois provavelmente a convivência com as pessoas do ambiente de trabalho e o respeito à diversidade contribuíram para a inclusão social. E ainda 
na percepção dos deficientes os demais trabalhadores não apresentaram atitudes preconceituosas nem discriminatórias e os valores estabelecidos na empresa favorecem as atitudes de cooperação e respeito dos funcionários. O único item de insatisfação avaliado nesta dimensão está relacionado à falta de sensibilização dos funcionários sobre a inclusão, identificada pelos deficientes visuais. Dessa forma, o Metrô-DF poderá implantar campanhas de sensibilização, nos quais estes indivíduos sejam protagonistas, afirmando suas habilidades e capacidades, conforme recomendado pela pesquisa desenvolvida por Neves-Silva et al. (2015) sobre inclusão de deficientes no mercado de trabalho.

Os valores obtidos na acessibilidade instrumental indicam que os equipamentos e instrumentos de trabalho apresentam poucos obstáculos para o desenvolvimento das atividades laborais, entretanto evidencia que, para os deficientes visuais a empresa poderá diminuir as barreiras existentes nessa dimensão, avaliando a necessidade de cada funcionário no exercício de suas atividades. As dificuldades na inclusão de pessoas com deficiência visual podem ser constatadas em uma pesquisa sobre possíveis contribuições da Tecnologia Assistiva - TA para a inclusão no trabalho. Na pesquisa de Sena (2015) verificou-se que, embora a disponibilidade da TA tenha aumentado, ainda permanece restrito o acesso dos trabalhadores com deficiência a esses dispositivos nas empresas. Ainda foi demonstrado que, os deficientes visuais podem exercer qualquer atividade relacionada ao uso do computador, através de softwares específicos, aprimorando as atividades exercidas, melhorando seu desempenho e permitindo uma comunicação eficiente com a equipe de trabalho.

Em relação à dimensão de acessibilidade arquitetônica, a média total ficou próxima da neutralidade. A instituição poderá realizar modificações no ambiente de trabalho para melhorar a locomoção das pessoas com deficiência, eliminando barreiras ou implantando soluções físicas de acesso. Os deficientes visuais foram indiferentes ao arranjo do ambiente de trabalho, o desenho e instalação dos mobiliários e sinalização de acesso. De acordo com Mendes (2009), o ambiente torna-se mais perceptível para o deficiente visual quando, há recursos disponíveis que beneficiam os sentidos sensoriais remanescentes, intensificando a interação do indivíduo com o meio através das sensações. Recurso que também pode ser utilizado para os deficientes auditivos, estimulando principalmente os aspectos visuais. Apesar das pessoas surdas possuírem uma singularidade visuo-espacial (WITCHS e LOPES, 
2018), obteve-se valores igualmente de neutralidade para o acesso, circulação, e nivelamento do piso para a locomoção sem barreiras.

A presença de obstáculos, intervindo na mobilidade dos deficientes e no reconhecimento dos espaços construídos, pode gerar um possível desgaste emocional, psicológico e físico, colocando o deficiente em situações de insegurança, ansiedade, medo e fracasso por não conseguirem se locomover de forma autônoma (SOARES et al., 2017). Entretanto, a acessibilidade arquitetônica impacta não apenas na segurança e autonomia das pessoas com deficiência quando na circulação dos ambientes, mas também na exclusão espacial dos indivíduos, conceito que considera o espaço como o agente de exclusão (DUARTE e COHEN, 1995).

O valor total da dimensão da acessibilidade metodológica sugere que os trabalhadores deficientes não possuem uma opinião ou não percebem as barreiras ou os acessos aos métodos e técnicas de trabalho. O mesmo foi observado por Coutinho et al. (2015) que registraram que a identificação dos obstáculos, por meio do próprio trabalhador poderia contribuir para o desenvolvimento de melhorias na execução das tarefas, pois as empresas possuem dificuldades no reconhecimento das capacidades e limitações da pessoa com deficiência, e nas intervenções necessárias para uma inclusão de qualidade.

Sabe-se que apenas as reservas de vagas de trabalho destinadas às pessoas deficientes não é o suficiente para a inclusão no ambiente laboral, sendo indispensável preparar essas pessoas para exercerem as mais diversas funções, de acordo com suas especialidades. No estudo realizado por Anand e Sevak (2017) com deficientes que solicitaram serviços de reabilitação em agências profissionais dos Estados Unidos foi identificado que pessoas com deficiência física são mais propícias a perceberem a falta de acessibilidade como uma barreira para acesso ao emprego e também os que menos receberam adequações em seus empregos atuais ou mais recentes. No Metrô-DF os deficientes visuais foram os que mais perceberam a falta de acessibilidade e os deficientes físicos foram neutros.

Levando em consideração que os deficientes visuais foram isentos ao avaliarem se receberam treinamento adequado e acessível para o melhor desempenho da função, os deficientes auditivos e físicos perceberam esse item de forma positiva. Validando o resultado, a pesquisa realizada por Maia e Carvalho-Freitas (2015) em duas instituições, corrobora com esses dados. Pois, embora as empresas não tenham utilizado estratégias específicas para 
contemplar os trabalhadores deficientes, o treinamento tem contribuído para o seu crescimento profissional. O estudo realizado por Assis e Carvalho-Freitas (2014) em uma organização de grande porte, demonstrou que o foco na qualificação profissional, além de contribuir com a aquisição de conhecimentos técnicos, poderá desenvolver habilidades comportamentais de autonomia, segurança e iniciativa, aspectos fundamentais para crescimento profissional dos trabalhadores deficientes. A oferta de programas acessíveis para preparação e desenvolvimento dos trabalhadores ultrapassa a aquisição de competências técnicas, e percorre por habilidades que favorecem a independência dos deficientes.

$\mathrm{Na}$ pesquisa sobre a importância da administração da cultura e do clima organizacional em uma organização do setor público desenvolvida por Souza et al. (2019) foi observado que os servidores não se sentem colaborativos nas questões de gestão, decisão e planejamento do órgão. Todavia, os deficientes auditivos e físicos do Metrô-DF não compartilham dessa mesma percepção. Eles consideram que a instituição, de forma parcial, proporciona condições para que possam assumir responsabilidades e tomar decisões, além de se sentirem a vontade em sugerir contribuições e melhorias para as atividades que realizam. Neste quesito, os deficientes visuais foram imparciais.

Em relação se as atividades que realizavam na empresa foram repensadas e adaptadas para serem executadas por uma pessoa com deficiência, os três tipos de deficiência foram neutros. Contudo, o item 6.6 do Edital n 1/2013 - Metrô-DF, que torna pública a realização de concurso público para provimento de vagas e formação do quadro de pessoal da companhia, menciona que as atividades dos empregados não serão modificadas para se adaptarem às condições especiais dos candidatos com deficiência. Cenário também observado na pesquisa realizada por Maia e Carvalho-Freitas (2015) que demonstrou que uma das empresas estudadas possui padrões que estabelece o problema da deficiência na própria pessoa e não no ambiente.

Considerando a dimensão programática, os dados de neutralidade, retratam que as empresas, ainda, poderiam melhorar suas práticas e políticas internas para tornar o ambiente de trabalho um local acessível. Evidenciaram também a necessidade de criação de políticas específicas para a gestão inclusiva dentro das empresas, modificando assim a cultura organizacional das instituições. Conforme, os resultados encontrados, a avaliação do item se as empresas possuem uma política de contratação de pessoas com qualquer deficiência, em 
qualquer grau e possuem condutas para a realização das atividades formuladas de acordo com as necessidades de uma pessoa com deficiência, obteve-se uma percepção neutra por parte dos deficientes físicos e visuais. Os auditivos possuem uma opinião positiva, corroborando com as informações obtidas no estudo de Assis e Carvalho-Freitas (2014), realizado em uma empresa de grande porte. A oportunidade de trabalho foi apresentada como o principal fator favorável, relativo ao programa de inclusão da empresa. Outros aspectos positivos citados foram à contratação de pessoas com diferentes formações, a diversidade de cargos em que estão trabalhando, a capacitação e o tratamento igualitário. Entretanto, a oportunidade de crescimento profissional foi o segundo maior aspecto de melhoria a ser realizada pela empresa. Alguns trabalhadores possuíam a percepção de que ocupavam cargos aquém da sua qualificação profissional, demonstrando que os deficientes ainda apresentavam suas capacidades laborais subestimadas e buscavam serem reconhecidos como profissionais qualificados. De modo semelhante nesta pesquisa, os deficientes visuais consideram que os programas, políticas de desenvolvimento e plano de carreira das empresas não fornecem condições às pessoas com deficiência de serem promovidas para novos cargos. Os deficientes auditivos e físicos avaliaram o item com neutralidade. Dessa forma, os programas e políticas de desenvolvimento e os planos de carreira poderiam melhorar seus aspectos para favorecer a promoção de pessoas com deficiência para novos cargos, aumentando assim, o engajamento e a motivação dos trabalhadores e possibilitando a criação e a valorização de novos talentos.

Na pesquisa realizada por Pereira (2011) em uma empresa de grande porte no Brasil, foi salientado que as modificações realizadas pela instituição não foram capazes de fomentar os resultados esperados para a inclusão dos trabalhadores deficientes, pois os métodos possuíam estereótipos pautados nos princípios impostos pelo mercado capitalista e pelas políticas públicas esbarrando na cultura da empresa e da sociedade. Reforçando essa análise, verificou-se que no edital nº 1/2013 - Metrô-DF, o concurso exigiu o teste de aptidão física para os cargos de Agente de Estação/OTM e Agente de Segurança/PSO. Estes foram os cargos, mais frequentes entre os trabalhadores deficientes neste estudo. $O$ teste de aptidão consistia em flexão abdominal, salto vertical, corrida (para ambos os sexos) e barra fixa (para os homens) e apesar de serem admitidos deficientes para esses cargos o edital não cita se as atividades físicas seriam adaptadas, de acordo com a necessidade de cada pessoa, garantindo a oportunidade de equidade entre os candidatos. Além disso, identificou-se a mesma falta de informação para a avaliação psicológica e para o curso de formação. Apenas as provas 
objetivas e subjetivas receberam adaptação para os candidatos que realizaram essa opção no momento da inscrição, indicando os recursos especiais necessários para a realização das provas. Entretanto, a solicitação do atendimento passou por critérios de viabilidade e de razoabilidade, podendo algum candidato deficiente ter sido prejudicado por falta de recursos apropriados. Também não foi evidenciada no edital a forma de resolução e avaliação das provas subjetivas para os deficientes auditivos que se comunicam através da Libras, uma vez que, para eles, o Português escrito é sua segunda língua (RAMOS e HAYASHI, 2019).

Pode-se considerar como limitação desta pesquisa a utilização de um questionário com questões fechadas, restringindo a identificação de outras variáveis necessárias para o aprimoramento da acessibilidade. Os trabalhadores podem ter experiências e compreensões além dos aspectos apresentados neste estudo. As modificações do local de trabalho provavelmente serão influenciadas por uma série de fatores suplementares, abrangendo rotinas laborais, funções de trabalho específicas, relacionamentos precedentes, políticas e culturas organizacionais. Dessa forma, estudos futuros podem explorar as dificuldades que os deficientes possuem e como elas se relacionam com seu ambiente de trabalho.

\section{CONSIDERAÇÕES FINAIS}

A questão da inclusão social tem tomado contornos mais efetivos e relevantes incluindo o acesso ao trabalho, em igualdade de oportunidades com relação às demais pessoas. Neste estudo foram identificadas as características e as percepções de acessibilidade dos trabalhadores com deficiência no metrô de Brasília, sob diferentes aspectos, identificando os fatores que influenciam a inclusão do trabalhador. A percepção dos trabalhadores para as dimensões de acessibilidade comunicacional, atitudinal, instrumental e arquitetônica foram positivas, o que pode ser observados nas médias alcançadas. Para a acessibilidade metodológica e programática, os trabalhadores foram neutros. A percepção do sujeito é uma relação com o seu meio e se essa conexão não existe, ele não consegue compreender o espaço onde trabalha, não agrega conhecimento e não o transforma. Diante disso, as práticas de promoção de acessibilidade da empresa devem estimular a participação dos deficientes, tornando-os colaboradores ativos para a construção de igualdade de condições no ambiente 
de trabalho. Sugerem-se aprimoramentos e novas estratégias inclusivas para que os deficientes possam exercer suas atividades laborais com segurança e autonomia.

A acessibilidade permite que trabalhadores com deficiência possam atender às expectativas de emprego e desempenhar as responsabilidades necessárias para o desenvolvimento das tarefas laborais. Embora o estudo tenha demonstrado vários aspectos que possam intervir na inclusão social de pessoas com deficiência no mercado de trabalho, mais pesquisas são importantes para entender melhor os desafios que existem no acesso a essas intervenções no ambiente de trabalho. Pesquisas adicionais que analisam quais adaptações beneficiam especificamente indivíduos com certas limitações podem ser importantes para futuras ações de acessibilidade auxiliando as instituições na tomada de decisões.

\section{REFERÊNCIAS}

ANAND, P., SEVAK, P. The role of workplace accommodations in the employment of people with disabilities. IZA Journal of Labor Policy, v. 6, n. 12, p. 1-20, 2017. Disponível em: <https://izajolp.springeropen.com/articles/10.1186/s40173-017-0090-4>. Acesso em: 24 Nov. 2019.

ASSIS, A., CARVALHO-FREITAS, M. Estudo de caso sobre a inserção de pessoas com deficiência numa organização de grande porte. REAd, v. 78, n. 2, p. 496-528, 2014. Disponível em: <https://www.scielo.br/scielo.php?pid=S141323112014000200496\&script=sci_abstract\&tlng=pt>. Acesso em: 25 Nov. 2019.

BARRETO, M., ALVES, M., MORAES, G. A acessibilidade nas empresas: percepção dos portadores de deficiência visual inseridos no mercado de trabalho. Simpósio de excelência em gestão e tecnologia. Resende, 2012. Disponível em: <https://www.aedb.br/seget/arquivos/artigos12/28516237.pdf>. Acesso em: 14 Jun. 2018.

BONACCIO, S., CONNELLY, C., GELLATLY, I., JETHA, A., GINIS, K. The participation of people with disabilities in the workplace across the employment cycle: employer concerns and research evidence. Journal of Business and Psychology, v. 35, p. 135-158, 2020. Disponível em: <https://link.springer.com/article/10.1007\%2Fs10869-018-96025>. Acesso em: 04 Jul. 2020.

BRASIL. Lei no 13.146, de 06 de julho de 2015. Institui a lei brasileira de inclusão da pessoa com deficiência (Estatuto da pessoa com deficiência). Diário Oficial da União; seção 1, Brasília, DF, p. 2, 07 jul 2015. Disponível em: <http://www.planalto.gov.br/ccivil_03/_ato2015-2018/2015/lei/113146.htm>. Acesso em: 24 Nov. 2018.

CIANTELLI, A., LEITE, L. Ações exercidas pelos núcleos de acessibilidade nas universidades federais brasileiras. Revista Brasileira de Educação Especial, v. 22, n. 3, p. 413-428, 2016 . Disponível em: <https://www.scielo.br/scielo.php?script=sci_abstract\&pid=S1413-65382016000300413\&lng=en\&nrm=iso\&tlng=pt>. Acesso em: 10 Dez. 2019.

COUTINHO, R., NOVIKOFF, C., MOREIRA, K., FRANCISCO, R. Tecnologia assistiva a favor da inclusão nas empresas: um estudo no ciberespaço. XI Congresso nacional de excelência em gestão. Rio de Janeiro, 2015. Disponível em: <http://www.inovarse.org/sites/default/files/T_15_123_11.pdf>. Acesso em: 25 Nov. 2019.

DUARTE, C., COHEN, R. Segregação e exclusão sócio-espacial: a questão dos portadores de deficiência física. IV Encontro nacional da ANPUR-UNB. Brasília, 1995. 
FELIZARDO, P., RONCHI, F., ROBAINA, G., PAIVA, E. Inclusão de pessoas com deficiência nas organizações e impacto no clima organizacional (CO). Revista da FAE, v. 1, p. 159-176, 2016. Disponível em: <https://revistafae.fae.edu/revistafae/article/view/412>. Acesso em: 10 Dez. 2019.

FRIEDNER, M. Deaf bodies and corporate bodies: new regimes of value in Bangalore's business process outsourcing sector. Journal of the Royal Anthropological Institute, v. 21, p. 313-329, 2015. Disponível em: <https://rai.onlinelibrary.wiley.com/doi/full/10.1111/1467-9655.12208>. Acesso em: 10 Dez. 2019.

FURLAN, F., RIBEIRO, S. O processo de inclusão no ensino superior: encontros e desencontros dos sujeitos que participam deste processo. Poiésis, v. 9, n. 16, 384-398, 2015. Disponível em: <http://www.portaldeperiodicos.unisul.br/index.php/Poiesis/article/view/3025>. Acesso em: 25 Nov. 2019.

GUSTAFSSON, J., PERALTA, J., DANERMARK, B. Supported employment and social inclusion - experiences of workers with disabilities in wage subsidized employment in Sweden. Scandinavian Journal of Disability Research, v. 20, n. 1, p. 26-36, 2018. Disponível em: <https://www.sjdr.se/articles/10.16993/sjdr.36/>. Acesso em: 04 Jul. 2020.

INSTITUTO BRASILEIRO DE GEOGRAFIA E ESTATÍSTICA (IBGE). 2010. Censo demográfico 2010. Disponível em: < https://censo2010.ibge.gov.br/resultados.html>. Acesso em: 02 Dez. 2019.

KUZNETSOVA, Y., BENTO, J. Workplace adaptations promoting the inclusion of persons with disabilities in mainstream employment: a case-study on employers' responses in Norway. Social Inclusion, v. 6, n. 2, p. 34-45, 2018. Disponível em: <https://www.ssoar.info/ssoar/handle/document/57370>. Acesso em: 04 Jul. 2020.

LORENZO, S., SILVA, N. Contratação de pessoas com deficiência nas empresas na perspectiva dos profissionais de recursos humanos. Revista Brasileira de Educação Especial, v. 23, n. 3, p. 345-360, 2017. Disponível em: <https://www.scielo.br/scielo.php?pid=S1413-65382017000300345\&script=sci_abstract\&tlng=pt>. Acesso em: 02 Dez. 2019.

MAIA, A., CARVALHO-FREITAS, M. O trabalhador com deficiência na organização: um estudo sobre o treinamento e desenvolvimento e a adequação das condições de trabalho. REAd, v. 82, n. 3, p. 689-718, 2015. Disponível em: <https://www.scielo.br/scielo.php?pid=S1413-23112015000300689\&script=sci_abstract\&tlng=pt>. Acesso em: 10 Dez. 2019.

MENDES, A. Avaliação das condições de acessibilidade para pessoas com deficiência visual em edificações em Brasília. 2009. Dissertação. (Mestrado em Arquitetura e Urbanismo) - Universidade de Brasília, Brasília, 2009. Disponível em: <https://repositorio.unb.br/handle/10482/6935>. Acesso em: 24 Nov. 2019.

MESSIAS, E. Pessoa com deficiência e mercado de trabalho: um olhar sobre as empresas de Viçosa-MG. Dissertação (Magister Scientiae) - Universidade Federal de Viçosa, Viçosa, 2018. Disponível em: <https://www.locus.ufv.br/bitstream/handle/123456789/21756/texto\%20completo.pdf?sequence=1\&isAllowed=y>. Acesso em: 04 Jul. 2020.

MINISTÉRIO DO TRABALHO. (MTb) 2018. Relação Anual de Informações Sociais 2018. Disponível em: <http://pdet.mte.gov.br/rais?view=default>. Acesso em: 02 Dez. 2019.

NEVES-SILVA, P., PRAIS, F., SILVEIRA, A. Inclusão da pessoa com deficiência no mercado de trabalho em Belo Horizonte, Brasil: cenário e perspectiva. Ciência e Saúde Coletiva, v. 20, n. 8, p. 2549-2558, 2015. Disponível em: <https://www.scielo.br/scielo.php?pid=S1413-81232015000802549\&script=sci_abstract\&tlng=pt>. Acesso em: 02 Dez. 2019.

ORGANIZAÇÃO INTERNACIONAL DO TRABALHO (OIT). 2018. Perspectivas sociais e de emprego no mundo: Tendências para Mulheres 2018. Disponível em: <https://www.ilo.org/global/about-theilo/newsroom/news/WCMS_619550?lang=es>. Acesso em: 28 Out. 2019.

OYINTONYO, M., LOVE, R., ENDURANCE U. Disability policies and people with special needs in the work environment in Bayelsa State, Nigeria. IfePsychologIA, v. 26, n. 2, p. 90-102, 2018. Disponível em: <https://www.ajol.info/index.php/ifep/article/view/178769>. Acesso em: 04 Jul. 2020.

PEREIRA, A. Inclusão de pessoas com deficiência no trabalho e o movimento da cultura organizacional: análise multifacetada de uma organização. 2011. Dissertação (Mestrado em Educação) - Universidade Federal do Rio Grande 
do Sul, Porto Alegre, 2011. Disponível em: <https://www.lume.ufrgs.br/handle/10183/29934>. Acesso em: 24 Nov. 2019.

PRINCE, M. Persons with invisible disabilities and workplace accommodation: findings from a scoping literature review. Journal of Vocational Rehabilitation, v. 46, p. 75-86, 2017. DOI 10.3233/JVR-160844. Disponível em: <https://content.iospress.com/articles/journal-of-vocational-rehabilitation/jvr844>. Acesso em: 04 Jul. 2020.

RAMOS, D., HAYASHI, M. Balanço das dissertações e teses sobre o tema educação de surdos (2010-2014). Revista Brasileira de Educação Especial, v. 25, n. 1, p. 117-132, 2019. Disponível em: <https://www.scielo.br/scielo.php?pid=S1413-65382019000100117\&script=sci_arttext>. Acesso em: 02 Dez. 2019.

ROSA, P., TORREL, E., PASQUALINI, L., FREITAS, C. Sobre interações entre estudantes surdos e ouvintes em classes inclusivas: o que dizem os professores?. VI Jornada de pesquisa em psicologia: pesquisa e tecnologia na psicologia atual. Santa Cruz do Sul, 2017. $<$ https://online.unisc.br/acadnet/anais/index.php/jornada_psicologia/article/view/17645>. Acesso em: 24 Nov. 2019.

SASSAKI, R. Inclusão: construindo uma sociedade para todos. 8. Rio de Janeiro: WVA, 2010.

SENA, S. Possíveis contribuições da tecnologia assistiva para a inclusão de pessoas com deficiência visual no trabalho. Revista Laborativa, v. 4, n. 2, p. 26-52, $2015 . \quad$ Disponível em: <https://ojs.unesp.br/index.php/rlaborativa/article/view/1241>. Acesso em: 24 Nov. 2019.

SIEBRA, I. A pessoa cega e a comunicação humana: um estudo das representações sociais. 2015. Dissertação. (Mestrado em Saúde da Comunicação Humana) - Universidade Federal do Pernambuco, Pernambuco, 2015. Disponível em: <https://repositorio.ufpe.br/handle/123456789/16259>. Acesso em: 25 Nov. 2019.

SILVA, G., SILVA, H. Para além da acessibilidade. Revista Includere, Mossoró, v. 1, ed. Especial, p. 204-206, 2015. Disponível em: < https://periodicos.ufersa.edu.br/index.php/includere/article/view/4601 >. Acesso em: 04 Jul. 2020.

SILVA, M., MIETO, G., OLIVEIRA, V. Estudos recentes sobre inclusão laboral da pessoa com deficiência intelectual. Revista Brasileira de Educação Especial, v. 25, n. 3, p. 469-486, 2019. Disponível em: <https://www.scielo.br/scielo.php?pid=S1413-65382019000300469\&script=sci_arttext>. Acesso em: 10 Dez. 2019.

SOARES, A., ALVES, R., TARGINO, E. Acessibilidade na arborização urbana: percepção de deficientes visuais sobre a mobilidade em espaços públicos arborizados. REVSBAU, v. 12, n. 3, p. 51-65, 2017. Disponível em: <https://revistas.ufpr.br/revsbau/article/view/63500>. Acesso em: 10 Dez. 2019.

SOUZA, M., SILVA, A., MEDEIROS, M., MELO, C., SILVA, I. A importância da administração da cultura e do clima organizacional: um estudo de caso na diretoria executiva do sistema de pagamento do estado de Rondônia. Revista Gestão e Negócios, v. $1, \quad$ p. $\quad 1-31, \quad 2019 . \quad$ Disponível em: <https://s3.uninove.br/app/uploads/2019/07/01135110/1562010670-1562010670-Magda.pdf>

WITCHS, P., LOPES, M. Forma de vida surda e seus marcadores culturais. Educação em Revista, v. 34, p. 1-17, 2018. Disponível em: <https://www.scielo.br/scielo.php?script=sci_abstract\&pid=S0102-

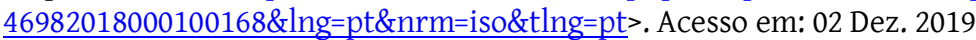

\section{(cc) Br}

Este trabalho está licenciado com uma Licença Creative Commons - Atribuição 4.0 Internacional. 